\title{
A FORMAÇÃO DE PROFESSORES DA EDUCAÇÃO PROFISSIONAL E TECNOLÓGICA NAS DIRETRIZES CURRICULARES PUBLICADAS PELO CONSELHO NACIONAL DE EDUCAÇÃO (2012 - 2018)
}

\author{
LA FORMACIÓN DE DOCENTES DE EDUCACIÓN PROFESIONAL Y \\ TECNOLÓGICA EN LAS PAUTAS CURRICULARES PUBLICADAS POR EL \\ CONSEJO NACIONAL DE EDUCACIÓN (2012 - 2018)
}

\section{TEACHER EDUCATION OF PROFESSIONAL AND TECHNOLOGICAL EDUCATION IN THE CURRICULAR GUIDELINES PUBLISHED BY THE NATIONAL COUNCIL OF EDUCATION (2012 - 2018)}

\author{
Susana TOZZETO ${ }^{1}$ \\ Thaiane de GOIS DOMINGUES ${ }^{2}$
}

RESUMO: A legislação que norteia a Educação Profissional e Tecnológica passou recentemente por alterações, assim como as exigências de formação para a docência nessa modalidade, trazendo a problemática à discussão. Este artigo tem assim por objetivo analisar a formação de professores na Educação Profissional e Tecnológica na legislação educacional. A pesquisa tem o caráter qualitativo, pautada na análise documental, que perpassa a legislação educacional, as Diretrizes Curriculares Nacionais publicadas pelo Conselho Nacional de Educação entre os anos de 2012 e 2018, assim como dissertações e teses sobre o tema. Conclui-se que a legislação atual não dialoga com os resultados recentes de pesquisas, principalmente no que tange à formação docente, que, segundo os estudos, não se baseiam somente na experiência profissional e não são considerados na possibilidade do notório saber para o exercício da docência na Educação Profissional e Tecnológica.

PALAVRAS-CHAVE: Educação Profissional e Tecnológica. Formação docente. Diretrizes Curriculares Nacionais.

RESUMEN: La legislación que orienta la Educación Profesional y Tecnológica em ocênci ocência nal por ocênci, así como las ocência $n$ de formación para la ocência em esa ocência $n$, trayendo la problemática a la discusión. Este artículo tiene por objetivo analizar la formación de ocência na em la Educación Profesional y Tecnológica em la legislación educativa. La investigación tiene el carácter cualitativo pautado em el análisis documental, que atraviesa la legislación educativa, las Directrices Curriculares Nacionales publicadas por el Consejo Nacional de Educación entre los años 2012 y 2018, así como disertaciones y tesis sobre el tema. Se concluye que la legislación actual no dialoga em los resultados recientes de investigaciones, principalmente em lo que se refiere a la formación docente, que, según los ocência, no se basan solamente em la experiencia ocência nal y

\footnotetext{
${ }^{1}$ Universidade Estadual de Ponta Grossa (UEPG), Ponta Grossa - PR - Brasil. Doutora em educação. Docente do Departamento de educação e do PPGE da UEPG. OrcID: http://orcid.org/0000-0002-1696-677X. E-mail: tozettosusana@hotmail.com

${ }^{2}$ Universidade Estadual de Ponta Grossa (UEPG), Ponta Grossa - PR - Brasil. Discente do PPG em Educação. OrcID: http://orcid.org/0000-0002-2291-8715. E-mail: thaicampos@hotmail.com
} 
no se consideran em la posibilidad del ocênci saber para el ejercicio de la educación ocência em la Educación Profesional y Tecnológica.

PALABRAS CLAVE: Educación Profesional y Tecnológica. Formación docente. Pautas nacionales de currículo.

ABSTRACT: The legislation that guides the Professional and Technological Education has recently undergone changes, as well as the education requirements for teaching in this modality, bringing the issue to discussion. This paper aims to analyze the education of teachers in Professional and Technological Education in educational legislation. The research has a qualitative character based on documentary analysis, which permeates the educational legislation, the National Curriculum Guidelines published by the National Council of Education between 2012 and 2018, as well as dissertations and theses on the subject. It is concluded that current legislation does not dialogue with recent research results, especially regarding teacher education, which, according to the studies, are not based only on professional experience and are not considered in the possibility of well-known knowledge for the exercise of teaching in Professional and Technological Education.

KEYWORDS: Professional and Technological Education. Teacher education. National Curriculum Guidelines.

\section{Introdução}

Em sua concepção, a Educação Profissional tinha como objetivo a retirada de crianças e adolescentes das ruas, dando-lhes formação para atividades profissionais. Por sua vez, o professor dessa modalidade, historicamente, pautou-se em um profissional que desenvolvesse bem suas atividades e conseguisse ensinar os procedimentos e as técnicas que dominava sobre uma profissão. Entretanto, o processo histórico de desvalorização da Educação Profissional e Tecnológica, por sua objetivação e pragmatismo, reflete-se, também, na falta de reconhecimento do papel e da relevância dos professores que atuam nessa modalidade de ensino. Em contrapartida, recentemente, a Educação Profissional e Tecnológica tem assumido um protagonismo em discussões acerca de sua reinserção no itinerário formativo do Ensino Médio, assim como o perfil de seu professor, trazendo à pauta o questionamento sobre a formação docente necessária para a oferta de um ensino de qualidade que supere a mera repetição de atividades em salas de aula e laboratórios.

O presente artigo tem assim por objetivo analisar a formação de professores para atuar na Educação Profissional e Tecnológica na legislação educacional. A análise perpassa a leis que antecedem e sucedem as Diretrizes e Bases da Educação Nacional (LDB) $n^{\circ}$ 9.394, de 20 de dezembro de 1996 (BRASIL, 1996) e culminam nas Diretrizes Curriculares Nacionais para 
a Formação de Profissionais do Magistério da Educação Básica (BRASIL, 2015) e nas Diretrizes Curriculares Nacionais para o Ensino Médio (BRASIL, 2018). Nesse sentido, questiona-se: qual formação se almeja para os professores da Educação Profissional e Tecnológica pela legislação que a rege?

O processo metodológico da pesquisa pautou-se em análise documental, da legislação e das pesquisas produzidas vinculadas ao tema. O texto discorre sobre os aspectos históricos da figura docente e da própria Educação Profissional e Tecnológica desde sua concepção no Brasil, avançando nos principais marcos legais acerca da educação que perpassam momentos políticos e econômicos do Brasil. Após o advento da Lei de Diretrizes e Bases da Educação Nacional - Lei no 9.394/1996 (BRASIL, 1996), das metas do Plano Nacional de Educação (BRASIL, 2014) e das diretrizes para formação de professores (BRASIL, 2015), refletindo a legislação do Conselho Nacional de Educação, as publicações vinculadas à Educação Básica e os recortes específicos da Educação Profissional e Tecnológica, bem como da formação de professores, são apresentados. Ao compreender que a legislação deve adequar o direcionamento da educação às necessidades e aos estudos da área, este texto apresenta as pesquisas e as publicações na Plataforma Sucupira entre os anos de 2013 e 2018 sobre os conhecimentos e a formação docentes na Educação Profissional e Tecnológica, de modo a relacionar os resultados obtidos e seu diálogo com os rumos adotados pela legislação atual.

\section{Histórico da docência na Educação Profissional}

A Educação Profissional e Tecnológica surge formalmente na história brasileira no ano de 1909, por meio do Decreto $\mathrm{n}^{\circ}$ 7.566, de 23 de setembro de 1909 (BRASIL, 1909), que, em seu texto, justificava seu estabelecimento, considerando:

[...] que o augmento constante da população das cidades exige que se facilite às classes proletarias os meios de vencer as dificuldades sempre crescentes da lueta pela existencia: que para isso se torna necessario, não só habilitar os filhos dos desfavorecidos da fortuna com o indispensavel preparo technico e intelectual, como faze-los adquirir habitos de trabalho proficuo, que os afastara da ociosidade ignorante, escola do vicio e do crime; que é um dos primeiros deveres do Governo da Republica formar codadões uteis à Nação. (BRASIL, 1909, p. 1).

Em seu texto, o decreto dá tratativa de que forma se operacionalizaria a Educação Profissional, com intermédio dos Ministérios da Agricultura, Indústria e Comércio, por meio de uma Escola de Aprendizes Artífices, destinada ao ensino profissional primário gratuito, em escolas da União, atendendo às especialidades das indústrias locais. Seus apontamentos, de 
ordem organizacional, apresentam a forma com que o funcionamento desses locais se dará, como serão subsidiados e seu público-alvo. Quanto aos seus funcionários, o Decreto coloca a necessidade do seguinte quadro:

Art. $4^{\circ}$. Cada escola terá um director, um escripturario, tantos mestres de officinas quantos sejam necessarios e um porteiro continuo. $\S 1^{\circ}$. O director será nomeado por decreto e vencerá 4:800\$ anuaes. $\S 2^{\circ}$. O escripturario e o porteiro-continuo serão nomeados por portaria do ministro, vencendo o primeiro 3:000\$ e o ultimo $1.800 \$$ annuaes. $\S 3^{\circ}$. Os mestres de officinas serão contractados por tempo não excedente a quatro annos, vencendo $200 \$$ mensaes além da quota a que se refere o art. 11 do presente decreto. (BRASIL, 1909, p. 2).

Os mestres de oficinas são assim os primeiros docentes, reconhecidos pela lei, da Educação Profissional e Tecnológica no Brasil, sem nenhuma referência à sua experiência ou formação, mas com uma observação de contratação não excedente a quatro anos. $\mathrm{Na}$ descrição das ocupações, é o mestre de oficinas, na função de docente, o último a ser listado. A Educação Profissional e Tecnológica caminha, então, no Brasil, e é inserida na Constituição de 1937 (BRASIL, 1937). Nela, aponta-se a destinação da Educação Profissional aos menos favorecidos e o dever das indústrias e dos sindicatos sobre a criação de escolas de aprendizes para os seus respectivos filhos. A Educação e a Cultura são abordadas do $128^{\circ}$ artigo ao $134^{\circ}$ (BRASIL, 1937), sem citações ou especificações sobre o exercício da docência na Educação Profissional que se consolidava à época no país.

Nos anos de 1940 tiveram início as ações da Reforma Capanema que, entre outros objetivos, buscava a estruturação de um ensino industrial e comercial no país, ressignificando a Educação Profissional do campo assistencialista para o de formação de mão de obra para um setor que estava se instituindo no país. O precursor desse processo foi o Serviço Nacional de Aprendizagem, Senai, criado por meio do Decreto-Lei $n^{\circ} 4048$, de 22 de janeiro de 1942 (BRASIL, 1942), com a proposta de organizar e administrar escolas de aprendizagem para industriários. Embora com a preposição de espaços de ensino em todo o país, nesse documento não há referência à operacionalização do processo de ensino dos alunos, assim como dos profissionais que o realizarão.

Somente em 1961 foi promulgada a primeira Lei de Diretrizes e Bases da Educação Nacional $n^{\circ}$ 4.024, de 20 de dezembro de 1961 (BRASIL, 1961). Segundo Caires e Oliveira (2016):

No campo da Educação Profissional a LDBEN/1961 estabeleceu a completa equivalência dos Cursos Técnicos com o Ensino Secundário, para efeito de ingresso no Ensino Superior. Foi permitida, também a matrícula no Ensino 
Médio, para os concluintes dos Cursos de Aprendizagem, em série adequada ao grau de estudo atingido na referida etapa. (CAIRES; OLIVEIRA, 2016, p. 71).

A Educação Profissional é vista assim como uma etapa da formação básica, porém a docência para a educação profissional é citada na referida lei de uma forma pouco delineada: “Art. 59. A formação de professores para o ensino médio será feita nas faculdades de filosofia, ciências e letras e a de professores de disciplinas específicas de ensino médio técnico em cursos especiais de educação técnica" (BRASIL, 1961, p. 11429). Os cursos especiais não são delimitados e aparentemente a formação exigida é do próprio curso profissionalizante, sem prever a formação para a docência.

O artigo 59 da LDBEN de 1961 (BRASIL, 1961) foi revogado pela Lei $\mathrm{n}^{\circ}$ 5.692, de 11 de agosto de 1971 (BRASIL, 1971), que modifica o ensino no país e divide-o em $1^{\circ}$ e $2^{\circ}$ graus. Em seu $4^{\circ}$ artigo, a lei delimita os currículos de cada etapa do ensino, colocando:

$\S 3^{\circ}$ Para o ensino de $2^{\circ}$ grau, o Conselho Federal de Educação fixará, além do núcleo comum, o mínimo a ser exigido em cada habilitação profissional ou conjunto de habilitações afins.

$\S 4^{\circ}$ Mediante aprovação do Conselho Federal de Educação, os estabelecimentos de ensino poderão oferecer outras habilitações profissionais para as quais não haja mínimos de currículo prèviamente estabelecidos por aquêle órgão, assegurada a validade nacional dos respectivos estudos. (BRASIL, 1971, p. 6377).

O que se vê na legislação é a compulsoriedade da habilitação profissional ao $2^{\circ}$ grau. Na mesma Lei (BRASIL, 1971), o Capítulo V dá tratativa aos professores e especialistas em educação sem se detalhar a formação para o ensino profissionalizante, ainda que inserido no $2^{\mathbf{o}}$ grau. Dessa forma, historicamente, a Educação Profissional e Tecnológica se constitui e tem sua execução pautada na transferência de habilidades adquiridas pela experiência profissional, caracterizando que, para ser docente nessa modalidade, o conhecimento pedagógico, o pensar à docência, não seria significativo.

Até a promulgação da Constituição Federal no Brasil em 1988 (BRASIL, 1988), novas formas de produção vão se apresentando pelo mundo do trabalho. A relação com o consumo se modifica e, por consequência, a mudança do ensino profissional (CAIRES; OLIVEIRA, 2016). O avanço da tecnologia, novas formas de comunicação, alterações nas relações de trabalho perpassam a escola, modificando o cenário da educação profissional. O primeiro passo é dado com o advento da Lei $\mathrm{n}^{0}$ 9.394/1996 (BRASIL, 1996), que estabelece as diretrizes e bases da educação nacional e apresenta em seus primeiros e segundo capítulos o vínculo e a finalidade da educação para a cidadania e para o trabalho. 
A mudança relevante no modelo de oferta da educação profissional dá-se por meio do Decreto $\mathrm{n}^{0}$ 2.208, de 17 de abril de 1997 (BRASIL, 1997), em que essa modalidade não teve mais a perspectiva de uma oferta integrada ao Ensino Médio. Passa a ter uma proposta curricular própria, prevendo que o ensino técnico se daria de forma concomitante, em contraturno ou de maneira subsequente, para alunos que já haviam finalizado essa etapa da sua formação. A formação docente nesse Decreto apresentava-se com a seguinte alusão:

Art. $9^{\circ}$ As disciplinas do currículo do ensino técnico serão ministradas por professores, instrutores e monitores selecionados, principalmente, em função de sua experiência profissional, que deverão ser preparados para o magistério, previamente ou em serviço, através de cursos regulares de licenciatura ou de programas especiais de formação pedagógica.

Parágrafo único. Os programas especiais de formação pedagógica a que se refere o caput serão disciplinados em ato do Ministro de Estado da Educação e do Desporto, ouvido o Conselho Nacional de Educação. (BRASIL, 1997, p. 7760).

A experiência profissional, basilar desde a concepção da Educação Profissional e Tecnológica, é redigida em lei como pré-requisito para a docência nessa modalidade. Apontase a necessidade do preparo para o magistério, antes ou durante a atuação do professor em sala de aula. Pode-se dizer que a formação pedagógica começa a ser percebida como necessária na Educação Profissional e Tecnológica, de uma forma tímida, e sem explicitar sua operacionalização. O tema de formação continuada para o professor do ensino técnico retorna à legislação, inerente às primeiras Diretrizes Curriculares Nacionais para a Educação Profissional de Nível Técnico, em 1999, em seu $17^{\circ}$ artigo, o qual aponta: “A preparação para o magistério na educação profissional de nível técnico se dará em serviço, em cursos de licenciatura ou em programas especiais" (BRASIL, 1999, p. 5).

Um diferencial na redação do documento, que se reflete diretamente na formação do aluno e no preparo docente, é a denominação de competências a serem atingidas na Educação Profissional e que passam a ser o requisito de saída do aluno na conclusão de seu curso. Assim sendo, os referenciais que surgiram, por área profissional e, posteriormente, os catálogos nacionais dos cursos técnicos ancoraram seus perfis profissionais de conclusão de curso, bem como seu itinerário formativo em competências. O professor que recebeu a educação baseada em objetivos e no desenvolvimento de um ser humano integral passa a se ver em sala de aula e laboratórios com a meta de desenvolvimento de competências profissionais gerais e específicas em seus alunos.

No ano de 2004, o Decreto $n^{\circ}$ 2.208, de 17 de abril de 1997 (BRASIL, 1997) é revogado, sendo substituído pelo Decreto n ${ }^{0}$ 5.154, de 23 de julho de 2004 (BRASIL, 2004), o 
qual reintegra a Educação Profissional ao Ensino Médio e mantém a oferta concomitante e subsequente dessa modalidade. Os cursos integrados têm sua carga horária revisitada de forma a desenvolver as disciplinas técnicas e a ementa da formação geral do Ensino Médio. Não há nenhuma menção à formação docente necessária para o exercício da docência, tanto nas modalidades concomitante e subsequente, bem como para a integrada. Subentende-se, dessa forma, que continua vigorando a formação requerida nas Diretrizes Curriculares de 1999 (BRASIL, 1999).

No ano de 2008, a Lei ${ }^{0} 11.741$, de 16 de julho de 2008 (BRASIL, 2008), altera a Lei de Diretrizes e Bases da Educação Nacional - Lei nº 9.394/1996 (BRASIL, 1996), com o propósito de redimensionar, institucionalizar e integrar as ações da Educação Profissional Técnica de Nível Médio, da Educação de Jovens e Adultos e da Educação Profissional e Tecnológica, que assume nova nomenclatura. Novamente, não há alusão no documento acerca da formação docente, ainda que inserindo a Educação de Jovens e Adultos à Educação Profissional.

A mensagem que foi aparentemente passada é que a Educação Profissional e Tecnológica passava por uma série de mudanças, incorporava a vertente tecnológica de reposicionamento da educação técnica às exigências de mercado e do capital. Contudo, a formação docente não foi problematizada, mantinha-se a figura do professor com experiência na área, formação técnica e uma alusão à sua formação em serviço, sem mais detalhamentos, prazos de execução ou programas específicos de seu desenvolvimento.

\section{As Diretrizes Curriculares correlatas à formação de professores e à Educação Profissional (2012-2018)}

Como apontado até o momento, os documentos norteadores datados até o ano de 2008 acerca da Educação Profissional e Tecnológica não discorriam de forma específica sobre a formação docente. O processo formativo docente passa a ser explicitado nas primeiras Diretrizes Curriculares da Educação Profissional Técnica de Nível Médio, no ano de 2012:

Art. 40 A formação inicial para a docência na Educação Profissional Técnica de Nível Médio realiza-se em cursos de graduação e programas de licenciatura ou outras formas, em consonância com a legislação e com normas específicas definidas pelo Conselho Nacional de Educação.

$\S 1^{\circ}$ Os sistemas de ensino devem viabilizar a formação a que se refere o caput deste artigo, podendo ser organizada em cooperação com o Ministério da Educação e instituições de Educação Superior.

$\S 2^{\circ}$ Aos professores graduados, não licenciados, em efetivo exercício na profissão docente ou aprovados em concurso público, é assegurado o direito 
de participar ou ter reconhecidos seus saberes profissionais em processos destinados à formação pedagógica ou à certificação da experiência docente, podendo ser considerado equivalente às licenciaturas:

I - Excepcionalmente, na forma de pós-graduação lato sensu, de caráter pedagógico, sendo o trabalho de conclusão de curso, preferencialmente, projeto de intervenção relativo à prática docente;

II - Excepcionalmente, na forma de reconhecimento total ou parcial dos saberes profissionais de docentes, com mais de 10 (dez) anos de efetivo exercício como professores da Educação Profissional, no âmbito da Rede CERTIFIC;

III - na forma de uma segunda licenciatura, diversa da sua graduação original, a qual o habilitará ao exercício docente.

$\S 3^{\circ} \mathrm{O}$ prazo para o cumprimento da excepcionalidade prevista nos incisos I e II do $\S 2^{\circ}$ deste artigo para a formação pedagógica dos docentes em efetivo exercício da profissão, encerrar-se-á no ano de 2020.

$\S 4^{\circ}$ A formação inicial não esgota as possibilidades de qualificação profissional e desenvolvimento dos professores da Educação Profissional Técnica de Nível Médio, cabendo aos sistemas e às instituições de ensino a organização e viabilização de ações destinadas à formação continuada de professores (BRASIL, 2012, p. 22).

O primeiro avanço dá-se, finalmente, ao apontar a formação superior como prérequisito para a docência na Educação Profissional e Tecnológica. As possibilidades de formação docente são clarificadas por meio da pós-graduação ou do reconhecimento de saberes profissionais para docentes com mais de dez anos de experiência, no entendimento de que, na escola, se deu uma formação em serviço e a licenciatura como uma opção para a habilitação como professor. Delimita, inclusive, que a formação pedagógica se efetive para todos os professores que atuam na Educação Profissional e Tecnológica em um prazo de oito anos, a se encerrar em 2020. Compreende-se que o professor estará sempre em formação, inclusive pelas próprias atualizações tecnológicas, que a educação profissional requisita uma constante lapidação de todo e qualquer professor e, assim, aponta-se para a necessidade de formação continuada frequente para os docentes da Educação Profissional e Tecnológica.

No ano de 2015, as Diretrizes para a Formação Inicial e Continuada dos Profissionais do Magistério da Educação Básica (BRASIL, 2015) são estabelecidas e, segundo Dourado (2015), colocam as seguintes perspectivas previstas para a formação docente: cursos de formação inicial de professores para a Educação Básica em nível superior, em cursos de licenciatura, organizados em áreas especializadas, por componente curricular ou por campo de conhecimentos e/ou interdisciplinar; cursos de formação pedagógica para graduados não licenciados, de caráter emergencial e provisório; cursos de segunda licenciatura. Como reflexo de um embasamento oriundo de discussões nas Conferências Nacionais de Educação (CONAE), entre os anos de 2010 e 2014, bem como de preposições do Plano Nacional de 
Educação (BRASIL, 2014-2024), o artigo $3^{\circ}$ das Diretrizes para a Formação Inicial e Continuada dos Profissionais do Magistério da Educação Básica reforça:

IV - A garantia de padrão de qualidade dos cursos de formação de docentes ofertados pelas instituições formadoras;

V - A articulação entre a teoria e a prática no processo de formação docente, fundada no domínio dos conhecimentos científicos e didáticos, contemplando a indissociabilidade entre ensino, pesquisa e extensão;

VI - O reconhecimento das instituições de educação básica como espaços necessários à formação dos profissionais do magistério;

VII - Um projeto formativo nas instituições de educação sob uma sólida base teórica e interdisciplinar que reflita a especificidade da formação docente, assegurando organicidade ao trabalho das diferentes unidades que concorrem para essa formação;

VIII - A equidade no acesso à formação inicial e continuada, contribuindo para a redução das desigualdades sociais, regionais e locais;

IX - A articulação entre formação inicial e formação continuada, bem como entre os diferentes níveis e modalidades de educação;

$\mathrm{X}$ - A compreensão da formação continuada como componente essencial da profissionalização inspirado nos diferentes saberes e na experiência docente, integrando-a ao cotidiano da instituição educativa, bem como ao projeto pedagógico da instituição de educação básica;

XI - A compreensão dos profissionais do magistério como agentes formativos de cultura e da necessidade de seu acesso permanente às informações, vivência e atualização culturais. (BRASIL, 2015, p. 13).

As Diretrizes para a Formação Inicial e Continuada dos Profissionais do Magistério da Educação Básica (BRASIL, 2015) trazem, em seu bojo, a formação de professores com foco na escola, enaltecendo o espaço escolar com suas problemáticas e peculiaridades, como norteador dos currículos e das ações dentro dos cursos de formação de professores. O novo paradigma, de uma formação de professores para a escola e articulada a ela, traz profundas implicações nas relações verticalizadas de teoria e prática, saberes acadêmicos e saber da prática nas licenciaturas. É válido reforçar que a formação pedagógica proposta para professores sem licenciaturas, em caráter emergencial, compreende que há a necessidade de um processo formativo para tais professores, consistente e normatizado, possibilitando que todos os professores da Educação Básica tenham o licenciamento e a devida preparação para tal.

As Diretrizes Curriculares da Educação Profissional Técnica de Nível Médio e Tecnológica (BRASIL, 2012) e as Diretrizes para a Formação Inicial e Continuada dos Profissionais do Magistério da Educação Básica (BRASIL, 2015), embora nos tragam prazos e proposições diferentes sobre a formação docente, complementam-se e fortalecem no sentido de identificar a necessidade de um professor que tenha uma formação técnica, o conhecimento 
do conteúdo a ser desenvolvido em sala de aula, mas que possa compreender e ter acesso ao conhecimento curricular, ao conhecimento pedagógico geral, chegando ao conhecimento pedagógico do conteúdo.

Os documentos, os prazos e as exigências, tangenciando seus textos, trariam por força de lei a mobilização de instituições de ensino, a conscientização e a valorização do conhecimento pedagógico em uma modalidade de ensino, mas não há tal reconhecimento. $\mathrm{O}$ ganho no processo de aprendizagem dos alunos, a qualidade de ensino e a perspectiva de mudança da concepção de uma modalidade de ensino que buscasse a formação integral do indivíduo estariam mais próximas. O professor da Educação Profissional e Tecnológica, com acesso aos conhecimentos docentes em sua integralidade, teria o entendimento do que, como e por que ensinaria, tendo assim intencionalidade em sua prática pedagógica que passaria a ser pautada não apenas na formação do aluno para o trabalho.

Ao analisar-se a trajetória da educação no Brasil, percebe-se que o processo não é fácil, rápido e simultâneo, mas as Diretrizes Curriculares da Educação Profissional Técnica de Nível Médio (BRASIL, 2012) e as Diretrizes para a Formação Inicial e Continuada dos Profissionais do Magistério da Educação Básica (BRASIL, 2015) nos apresentam melhores perspectivas para pensar acerca da formação docente na Educação Profissional e Tecnológica. Entretanto, retrocede-se um caminho, que há tempo se construía, e contrapõe-se a todos os documentos norteadores da formação docente, com a promulgação da Lei n ${ }^{0} 13.415$, de 16 de fevereiro de 2017 (BRASIL, 2017). Nela, a Educação Profissional e Tecnológica sofre uma nova alteração, remetendo aos seus insucessos pretéritos e retornando ao texto do Ensino Médio, alterando novamente a Lei no 9.394/1996 (BRASIL, 1996):

Art. 36. O currículo do ensino médio será composto pela Base Nacional Comum Curricular e por itinerários formativos, que deverão ser organizados por meio da oferta de diferentes arranjos curriculares, conforme a relevância para o contexto local e a possibilidade dos sistemas de ensino, a saber: I linguagens e suas tecnologias; II - matemática e suas tecnologias; III ciências da natureza e suas tecnologias; IV - ciências humanas e sociais aplicadas; V - formação técnica e profissional. (Redação dada pela Lei $\mathrm{n}^{\circ}$ 13.415, de 2017). (BRASIL, 2017, p. 1).

No que tange à formação docente, a Lei $n^{0}$ 13.415/2017 altera, da mesma forma, a LDB (BRASIL, 1996), legalizando o notório saber como requisito para o exercício da docência no Ensino Médio:

Art. $6^{\circ} \mathrm{O}$ art. 61 da Lei $\mathrm{n}^{\circ}$ 9.394, de 20 de dezembro de 1996, passa a vigorar com as seguintes alterações: 
IV - Profissionais com notório saber reconhecido pelos respectivos sistemas de ensino, para ministrar conteúdos de áreas afins à sua formação ou experiência profissional, atestados por titulação específica ou prática de ensino em unidades educacionais da rede pública ou privada ou das corporações privadas em que tenham atuado, exclusivamente para atender ao inciso $\mathrm{V}$ do caput do art. 36;

V - Profissionais graduados que tenham feito complementação pedagógica, conforme disposto pelo Conselho Nacional de Educação. (BRASIL, 2017, p. 2).

O notório saber, da forma com que se apresenta, encerra e enterra todo um processo de conscientização que vinha sendo constituído pela legislação e diretrizes do Conselho Nacional de Educação, que buscava um professor na Educação Profissional e Tecnológica que ultrapassasse a transmissão de informação ou técnicas. Propõe-se a docência para profissionais que possuem apenas o domínio de sua atividade profissional de origem, específica. Subentende-se, assim, que não existe a necessidade de formação pedagógica para a docência. Tal posicionamento desvaloriza e reforça a discrepância histórica da Educação Profissional e Tecnológica quanto à sua finalidade, de atendimento aos desvalidos da sorte, que necessitam tão somente de alguém que os ensine a fazer, com um professor sem conhecimento acerca da formação humana do aluno.

Após a homologação da Lei $n^{0}$ 13.415/2017 (BRASIL, 2017), deu-se início, no Conselho Nacional de Educação, à constituição de diretrizes que embasassem a operacionalização da referida Lei. Assim, no ano de 2018, após a análise da Lei do Ensino Médio, o Conselho Nacional de Educação homologa a atualização das Diretrizes Curriculares Nacionais para o Ensino Médio sob o Parecer CNE/CEB no 3, de 8 de novembro de 2018 (BRASIL, 2018), de forma que as mudanças previstas pela Lei fossem clarificadas em sua operação. A formação docente para o Ensino Médio reforça e complementa a Lei $n^{\circ}$ 13.415/2017 e integra o $4^{\circ}$ título do documento, no que concerne às Disposições Gerais e Transitórias:

Art. 28. A formação de docentes para atuar no ensino médio far-se-á em nível da educação superior, em cursos de licenciatura.

Art. 29. Profissionais com notório saber reconhecido pelos respectivos sistemas de ensino podem atuar como docentes do ensino médio apenas no itinerário de formação técnica e profissional para ministrar conteúdos afins à sua formação ou experiência profissional, devidamente comprovadas, conforme inciso IV do art. 61 da LDB.

Parágrafo único. A docência nas instituições e redes de ensino que ofertam o itinerário de formação técnica e profissional poderá ser realizada por profissionais com comprovada competência técnica referente ao saber operativo de atividades inerentes à respectiva formação técnica e profissional. 
Art. 30. Podem ser admitidos para a docência no ensino médio, profissionais graduados que tenham realizado programas de complementação pedagógica ou concluído curso de pós-graduação stricto sensu, orientado para o magistério na educação básica. (BRASIL, 2018, p. 24).

Nas Diretrizes Curriculares para o Ensino Médio (BRASIL, 2018), apresentam-se assim somente três artigos que arbitram sobre a formação docente. Neles se reforça a mera expectativa de competência técnica do saber operativo vinculado à formação técnica e profissional do professor da Educação Profissional e Tecnológica. Assim, por meio dessas Diretrizes, os conhecimentos pedagógicos não são valorizados e apontados como necessários ao exercício da docência na Educação Profissional e Tecnológica. Limitar o notório saber ao conhecimento necessário para o exercício da docência na Educação Profissional reposiciona o país ao entendimento de que, para ser professor, basta saber algo, sem a devida preparação acadêmica para tal. Preocupa de forma demasiada os objetivos subliminares desse processo, correlacionando a fragilidade da formação docente à fragilidade de formação humana e crítica do aluno da Educação Profissional e Tecnológica.

\section{Conhecimento e formação docente para a Educação Profissional - o que apontam as pesquisas}

Ao partir-se do princípio de que alterações na legislação almejam atender às necessidades identificadas, buscou-se analisar a relação entre a realidade retratada por pesquisas acerca da formação e dos conhecimentos docentes e o direcionamento legal atual proposto para os professores da Educação Profissional e Tecnológica. Tal pesquisa deu-se na Plataforma Sucupira, repositório da Coordenação de Aperfeiçoamento de Pessoal de Nível Superior (CAPES), abrangendo os anos de 2013 até 2017, para análise de dissertações e de teses já produzidas acerca do conhecimento docente na Educação Profissional. Inicialmente, lançaram-se os termos de pesquisa: educação profissional, bacharel, licenciado e conhecimento docente, de forma a identificar pesquisas que estivessem no campo da Educação Profissional e Tecnológica, pautadas no perfil docente dessa modalidade, sob o olhar do desenvolvimento do conhecimento docente. Chegou-se, assim, ao universo de 3.559 pesquisas. Como o objetivo era aprofundar o estudo em resumos e nos textos integrais das pesquisas, circunscreveu-se a busca às produções temporalmente datadas entre 2013 até 2017, pela possibilidade de consulta do trabalho na íntegra, reduzindo-se, dessa forma, a amostragem para 1.656 dissertações e teses. 
Na sequência, o recorte deu-se selecionando-se áreas de conhecimento, chegando-se à 963 dissertações e teses que tiveram a leitura de seus títulos para análise da aderência ao universo que estava sendo pesquisado. Foram selecionados 34 trabalhos que faziam alusão ao desenvolvimento do conhecimento docente na Educação Profissional e Tecnológica. Após o estudo das introduções e das conclusões dos trabalhos, encontraram-se 14 dissertações e 3 teses cujos objetivos e temática eram afins ao buscado, assim como traziam contribuições para a análise dos conhecimentos e das práticas dos professores da Educação Profissional e Tecnológica no Brasil.

Em sua maioria, as pesquisas deram-se em Instituições Públicas de ensino e eram referentes ao ensino profissional subsequente, tinham em comum o interesse em compreender como se dava o desenvolvimento dos conhecimentos docentes e as influências nas práticas pedagógicas, de uma forma preponderante de bacharéis atuantes na Educação Profissional e Tecnológica. As dezessete pesquisas trouxeram que, em grande parte, o desenvolvimento da docência, pela formação em bacharelados e cursos superiores de tecnologia, se dá por meio da formação continuada e que a influência na prática pedagógica é em decorrência dessa formação já em serviço. Assim, a prática consolida-se com as experiências em sala de aula, apontamentos de colegas de trabalho, apoio pedagógico, porém o histórico do professor, como ex-aluno, influencia significativamente em sua postura em sala de aula.

No que tange aos conhecimentos docentes, a grande maioria dos pesquisados das dissertações e das teses analisadas valorizava o conhecimento do conteúdo, adquirido na graduação e na atuação profissional que antecede ou é concomitante à docência. No entanto, os professores abordados nas pesquisas, em sua maioria, reconheciam o quanto os conhecimentos pedagógicos são importantes e seu desconhecimento impacta na prática docente. Por consequência, embora identificando a formação em serviço, os docentes demonstraram, em suas respostas às pesquisas desenvolvidas, a necessidade de uma formação apropriada para a docência e não somente por meio do aprender fazendo, quando já se encontram em sala de aula.

Ao analisarem-se as pesquisas realizadas neste espaço de tempo, 2013-2017, concluise que os professores atuantes da Educação Profissional e Tecnológica reconhecem a falta de conhecimentos pedagógicos que embasem sua prática pedagógica, assim como o impacto que esse desconhecimento gera em sua atuação docente. O que mais surpreende é que, ainda que sob o olhar dos pesquisadores e com os resultados publicados apontando a necessidade da formação docente, do reconhecimento que os saberes experienciais e disciplinares não estão se bastando para o exercício da docência na Educação Profissional e Tecnológica, promulga- 
se uma lei no final do ano de 2017 - a Lei n ${ }^{0}$ 13.415/2017, do Novo Ensino Médio (BRASIL, 2017), assim como Diretrizes Curriculares Nacionais para o Ensino Médio (BRASIL, 2018), que arbitram na contracorrente do pesquisado e apontado nas Universidades brasileiras.

\section{Considerações finais}

A exemplo da documentação do ano de 1909, que se predispunha a uma formação de mão de obra para desvalidos com o propósito de prepará-los tão somente para o trabalho, quando bastava um professor que soubesse ensinar o aluno a apertar o parafuso, atividade que tinha domínio pela prática laborativa, a documentação norteadora atual posta para a docência na Educação Profissional retoma os tempos remotos ao propor o mesmo perfil docente. $\mathrm{O}$ professor somente com o conhecimento adquirido em uma formação bacharelesca, tecnológica ou por meio de uma prática profissional consolidada não consegue desenvolver todos os saberes necessários à docência, influenciando totalmente sua prática pedagógica com processos que se pautam na transmissão de conhecimento, somente. Necessita-se de formação docente em específico para a Educação Profissional e Tecnológica, não somente para o processo formativo, mas também para a imersão na tecnologia, exigência que os professores percebem e demonstram nas pesquisas consultadas.

Ao analisar o histórico da docência da Educação Profissional, os avanços das Diretrizes Curriculares da Educação Profissional (BRASIL, 2012) e das Diretrizes Curriculares de Formação de Professores (BRASIL, 2015), o retrocesso e a incoerência do mesmo Conselho Nacional de Educação nas Diretrizes Curriculares do Ensino Médio (BRASIL, 2018) são evidentes. Embora os prazos propostos acerca das Diretrizes da Educação Profissional e da Formação Docente sejam diferentes e com apontamentos, ora para a formação complementar, ora para uma formação docente provisória, os documentos e seus objetivos eram convergentes. Pondo fim às discussões e a um processo de conscientização e organização de instituições de ensino e seus professores com formação em nível técnico, tecnológico ou bacharelado acerca da necessidade de uma constituição de docência que os preparasse para o ensino, as novas Diretrizes Curriculares do Ensino Médio (BRASIL, 2018), além de segregarem os alunos do Ensino Médio na restrição de acesso a itinerários formativos, banalizam os conhecimentos necessários para a docência na Educação Profissional e Tecnológica.

Ao finalizar a análise acerca das Diretrizes Curriculares publicadas entre os anos de 2012 e 2018 do Conselho Nacional de Educação, ficam claras as divergências existentes em 
textos vigentes acerca do entendimento da importância e dos critérios sobre a formação de professores para a Educação Profissional e Tecnológica. Propõe-se, desta forma, que dentre as publicações do Conselho Nacional de Educação a formação de professores para a Educação Profissional seja revisitada, de maneira a atender as necessidades e lacunas identificadas na realidade das escolas.

Frente a tal proposição, também se sugere que as escolas que ofertam a Educação Profissional compreendam que a formação de alunos de caráter emancipador perpassa o trabalho docente. Com base nessa premissa, que sejam ofertadas formações continuadas com o enfoque nos conhecimentos docentes de forma a, dentro do contexto escolar, propiciar uma Educação Profissional de melhor qualidade.

Neste contexto, é importante considerar as pesquisas acadêmicas realizadas nas Universidades brasileiras acerca do tema, que poderão vir a contribuir para um itinerário formativo docente no espaço da escola. A formação continuada poderá subsidiar, assim, uma articulação entre os conhecimentos específicos e os conhecimentos pedagógicos para o professor e a constituição emancipatória do aluno.

\section{REFERÊNCIAS}

BRASIL. [Constituição (1988)]. Constituição da República Federativa do Brasil. Brasília, DF: Senado, 1988.

BRASIL. [Constituição (1937)]. Constituição dos Estados Unidos do Brasil de 1937. Rio de Janeiro, [1937]. Disponível em:

http://www.planalto.gov.br/ccivil_03/Constituicao/Constituicao37.htm. Acesso em: 25 jan. 2019.

BRASIL. Decreto n. 7.566, de 23 de setembro de 1909. Rio de Janeiro, 1909. Créa nas capitaes dos Estados da Escolas de Aprendizes Artífices, para o ensino profissional primario e gratuito. Disponível em: http://portal.mec.gov.br/setec/arquivos/pdf3/decreto_7566_1909.pdf. Acesso em: 25 jan. 2019.

BRASIL. Decreto n. 2.208, de 17 de abril de 1997. Diário Oficial da União: seção 1, Brasília, DF, n. 274, p. 7760-7761, 18 abr. 1997.

BRASIL. Decreto-Lei n. 4.048, de 22 de janeiro de 1942. Cria o Serviço Nacional de Aprendizagem dos Industriários (SENAI). Diário Oficial da União, 1942. Disponível em: http://www.planalto.gov.br/ccivil_03/decreto-lei/1937-1946/Del4048.htm. Acesso em: 25 jan. 2019.

BRASIL. Decreto n. 5.154, de 23 de julho de 2004. Regulamenta o $§ 2$ - do art. 36 e os arts. 39-41 da Lei n. 9.394, de 20 de dezembro de 1996, que estabelece as diretrizes e bases da 
educação nacional, e dá outras providências. Diário Oficial da União: seção 1, Brasília, DF, n. 142, p. 18, 26 jul. 2004.

BRASIL. Lei n. 4.024, de 20 de dezembro de 1961. Fixa as diretrizes e bases da educação nacional. Diário Oficial da União: seção 1, Brasília, DF, p. 11.429, 27 dez. 1961.

BRASIL. Lei n. 5.692, de 11 de agosto de 1971. Fixa as diretrizes e bases da educação nacional. Diário Oficial da União: seção 1, Brasília, DF, p. 6377, 12 ago. 1971.

BRASIL. Lei n. 9.394, de 20 de dezembro de 1996. Estabelece as diretrizes e bases da educação nacional. Diário Oficial da União: seção 1, Brasília, DF, n. 248, p. 27833-27841, 23 dez. 1996.

BRASIL. Lei n. 11.741, de 16 de julho de 2008. Altera dispositivos da Lei n. 9.394,de 20 de dezembro de 1996, que estabelece as diretrizes e bases da educação nacional, para redimensionar, institucionalizar e integrar as ações da educação profissional técnica de nível médio, da educação de jovens e adultos e da educação profissional e tecnológica. Diário Oficial da União: seção 1, Brasília, DF, n. 136, p. 5-6, 17 jul. 2008.

BRASIL. Lei n. 13.005, de 25 de junho de 2014. Aprova o Plano Nacional de Educação (PNE) e dá outras providências. Diário Oficial da União: seção 1, Brasília, DF, n. 120-A, edição extra, p. 1-7, 26 jun. 2014.

BRASIL. Lei n. 13.415, de 16 de fevereiro de 2017. Altera as Leis n. 9.394, de 20 de dezembro de 1996, que estabelece as diretrizes e bases da educação nacional, e 11.494, de 20 de junho 2007, que regulamenta o Fundo de Manutenção e Desenvolvimento da Educação Básica e de Valorização dos Profissionais da Educação, a Consolidação das Leis do Trabalho - CLT, aprovada pelo Decreto-Lei n. 5.452, de 10 de maio de 1943, e o Decreto-Lei no 236, de 28 de fevereiro de 1967; revoga a Lei n. 11.161, de 5 de agosto de 2005; e institui a Política de fomento à implementação de escolas de ensino médio em tempo integral. Diário Oficial da União: seção 1, Brasília, DF, n. 35, p. 1-3, 17 fev. 2017.

BRASIL. Parecer n. 2, de 9 de junho de 2015. Diretrizes curriculares nacionais para a formação inicial e continuada dos profissionais do magistério da educação básica. Diário Oficial da União: seção 1, Brasília, DF, n. 119, p. 13, 25 jun. 2015.

BRASIL. Resolução CNE/CEB n. 4, de 8 de dezembro de 1999. Institui as diretrizes curriculares nacionais para a educação profissional de nível técnico. Brasília: CNE/CEB, 1999. Disponível em: http://portal.mec.gov.br/dmdocuments/rceb004_99.pdf. Acesso em: 25 jan. 2019.

BRASIL. Ministério da Educação. Conselho Nacional de Educação. Câmara de Educação Básica. Resolução n. 3, de 21 de novembro de 2018. Atualiza as Diretrizes Curriculares Nacionais para o Ensino Médio. Diário Oficial da União: seção 1, Brasília, DF, ano 155, n. 224, p. 21-24, 22 nov. 2018.

BRASIL. Ministério da Educação. Conselho Nacional de Educação. Câmara de Educação Básica. Resolução n. 6, de 20 de setembro de 2012. Define diretrizes curriculares nacionais para a educação profissional técnica de nível médio. Diário Oficial da União: seção 1, Brasília, DF, ano 149, n. 184, p. 22, 21 set. 2012. 
CAIRES, V. G.; OLIVEIRA, M. A. M. Educação Profissional Brasileira: da colônia ao PNE 2014-2024. Petrópolis: Vozes, 2016.

DOURADO, L. F. Diretrizes Curriculares Nacionais para a formação inicial e continuada dos profissionais do magistério da educação básica: concepções e desafios. Educação \&

Sociedade, Campinas, v. 36. n. 131, p. 299-324, abr./jun. 2015. DOI:

http://dx.doi.org/10.1590/ES0101-73302015151909

\section{Como referenciar este artigo}

TOZZETO, Susana.; GOIS DOMINGUES, Thaiane de. A formação de professores da Educação Profissional e Tecnológica nas Diretrizes Curriculares publicadas pelo Conselho Nacional de Educação (2012 - 2018). Revista Ibero-Americana de Estudos em Educação, Araraquara, v. 15, n. 1, p. 172-188, jan./mar. 2020. e-ISSN: 1982-5587. DOI: https://doi.org/10.21723/riaee.v15i1.12151

Submetido em: 30/01/2019

Revisões requeridas: 10/03/2019

Aprovado em: 20/05/2019

Publicado em: 02/01/2020 